Chapman University

Chapman University Digital Commons

5-15-2018

Insertion and Presence of Fine-wire Intramuscular Electrodes to the Lumbar Paraspinal Muscles Do Not Affect Muscle Performance and Activation during Highexertion Spinal Extension Activities

Szu-Ping Lee

Jo Armour Smith

Matthew Kimber

Kelsey Houk

Follow this and additional works at: https://digitalcommons.chapman.edu/pt_articles 


\section{Insertion and Presence of Fine-wire Intramuscular Electrodes to the Lumbar Paraspinal Muscles Do Not Affect Muscle Performance and Activation during Highexertion Spinal Extension Activities}

\section{Comments}

NOTICE: this is the author's version of a work that was accepted for publication in $P M \& R$. Changes resulting from the publishing process, such as peer review, editing, corrections, structural formatting, and other quality control mechanisms may not be reflected in this document. Changes may have been made to this work since it was submitted for publication. A definitive version was subsequently published in $P M \mathcal{H}^{\prime} R$ in 2018 .

DOI:10.1016/j.pmrj.2018.05.006

The Creative Commons license below applies only to this version of the article.

\section{Creative Commons License} (c) $($ ) $(9)$

This work is licensed under a Creative Commons Attribution-Noncommercial-No Derivative Works 4.0 License.

\section{Copyright}

American Academy of Physical Medicine and Rehabilitation 


\section{Accepted Manuscript}

Insertion and Presence of Fine-wire Intramuscular Electrodes to the Lumbar Paraspinal Muscles Do Not Affect Muscle Performance and Activation during Highexertion Spinal Extension Activities

Szu-Ping Lee, PT, PhD, Jo Armour Smith, PT, PhD, Matthew Kimber, PT, DPT,

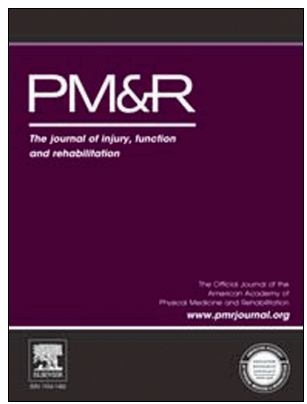
Kelsey Houk, BS

PII:

$$
\text { S1934-1482(18)30236-3 }
$$

DOI:

$$
\text { 10.1016/j.pmrj.2018.05.006 }
$$

Reference: PMRJ 2112

To appear in: $\quad P M \& R$

Received Date: 9 November 2017

Revised Date: 26 April 2018

Accepted Date: 5 May 2018

Please cite this article as: Lee S-P, Smith JA, Kimber M, Houk K, Insertion and Presence of Finewire Intramuscular Electrodes to the Lumbar Paraspinal Muscles Do Not Affect Muscle Performance and Activation during High-exertion Spinal Extension Activities, PM\&R (2018), doi: 10.1016/ j.pmrj.2018.05.006.

This is a PDF file of an unedited manuscript that has been accepted for publication. As a service to our customers we are providing this early version of the manuscript. The manuscript will undergo copyediting, typesetting, and review of the resulting proof before it is published in its final form. Please note that during the production process errors may be discovered which could affect the content, and all legal disclaimers that apply to the journal pertain. 
Insertion and Presence of Fine-wire Intramuscular Electrodes to the Lumbar Paraspinal Muscles Do Not Affect Muscle Performance and Activation during High-exertion Spinal Extension Activities

Szu-Ping Lee, PT, $\mathrm{PhD}^{1}$

Jo Armour Smith, PT, $\mathrm{PhD}^{2}$

Matthew Kimber, PT, DPT ${ }^{1}$

Kelsey Houk, BS ${ }^{1}$

${ }^{1}$ Department of Physical Therapy, University of Nevada, Las Vegas, Nevada, USA

${ }^{2}$ Department of Physical Therapy, Chapman University, Orange, California, USA

This study was supported by the University of Nevada, Las Vegas, Department of Physical Therapy, Student Opportunity Research Grant.

Corresponding author:

Szu-Ping Lee, PT, PhD

Department of Physical Therapy, University of Nevada, Las Vegas 4505 S. Maryland Parkway, Box 453029, Las Vegas, NV 89154-3029, USA

Phone: (702)895-3086

Fax: (702)895-4883

Email: szu-ping.lee@unlv.edu 
2 Lumbar Paraspinal Muscles Do Not Affect Muscle Performance and Activation 


\section{ABSTRACT}

Background: Low back pain (LBP) is commonly associated with paraspinal muscle dysfunctions. A method to study deep lumbar paraspinal (i.e. multifidus) muscle function and neuromuscular activation pattern is intramuscular electromyography (EMG). Previous studies have shown that the procedure does not significantly impact muscle function during activities involving low-level muscle contractions. However, it is currently unknown how muscular function and activation are affected during high-exertion contractions.

Objective: To examine the effects of insertion and presence of fine-wire EMG electrodes in the lumbar multifidus on muscle strength, endurance, and activation profiles during high-exertion spinal extension muscle contractions.

Design: Single-blinded, repeated measures intervention trial.

Setting: University clinical research laboratory

Participants: Twenty individuals between the ages of 18-40 free of recent and current back pain.

Methods: Muscle performance was assessed during 3 conditions (with [WI] and without [WO] presence of intramuscular electrodes, and insertion followed by removal [IO]). Isometric spinal extension strength was assessed with a motorized dynamometer. Muscle endurance was assessed using the Sorensen test with neuromuscular activation profiles analyzed during the endurance test.

Main Outcome Measurements: Spinal extensor muscle strength, endurance, and activation.

Results: Our data showed no significant difference in isometric strength $(\mathrm{p}=.20)$ between the 3 conditions. A significant difference in muscle endurance was found $(\mathrm{p}=.03)$. Post-hoc analysis showed that the muscle endurance in the IO condition was significantly higher than the WO condition $(161.3 \pm 58.3$ vs. 
$45 \quad 142.1 \pm 48.2 \mathrm{sec}, \mathrm{p}=.04$ ), likely due to a learning effect. All 3 conditions elicited minimal pain (range 0-

$464 / 10)$ and comparable muscle activation profiles.

47 Conclusion: Our findings suggested the sonographically guided insertion and presence of fine-wire

48 intramuscular EMG electrodes in the lumbar multifidus muscles had no significant impact on spinal

49 extension muscle function. This study provides evidence that implementing intramuscular EMG does not

50 affect muscle performance during high-exertion contractions in individuals with no current back pain.

51

52

53

54

55

56

57

58

59

60

61

62

63 58 64

Key words: electromyography, intramuscular insertion, lower back pain, multifidus

Level of Evidence: II

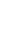

4

\section{(1)} 59 60 61 62 63 


\section{Introduction}

Almost $40 \%$ of the global population experience at least an episode of low back pain (LBP) at some point in their lifetime.[1] One theoretical cause of LBP is spinal instability. Panjabi described that spinal stability is constituted of 3 subsystems: passive (bones, joints, and non-contractile tissues), active (muscles), and neural control (sensorimotor reflexes).[2] Crisco et al. demonstrated the importance of the active stability system that a cadaveric spine with all muscles removed will buckle under a load well below normal physiological levels.[3] Perhaps the most important muscle for maintaining spinal stability is the lumbar multifidus.[4,5,6] These deep paraspinal muscles are made up of short fibers that cross 1-2 spinal segments, which allows the muscle to control intersegmental rotations and resist shear forces thus providing structural stability.[7] Kjaer et al. found that atrophy and fatty infiltration of the lumbar multifidus, implying muscle dysfunction, are significantly related to LBP.[8]

A common method to assess muscle function is electromyography (EMG). Both surface EMG and intramuscular EMG with indwelling fine-wire electrodes are commonly used for spinal research.[9,10] Surface EMG is limited by myoelectric cross-talk and has been shown to be less valid in detecting activations of deep paraspinal muscles such as the multifidus.[11] Intramuscular EMG can target specific muscles if the fine-wire electrodes are inserted under sonographic guidance. Although intramuscular EMG is more suited to study the activation of deep paraspinal muscles, it has the potential disadvantage of altering motor behavior due to the pain associated with insertion and/or presence of the intramuscular electrodes during muscle contractions. For example, previous studies have shown that muscles in a state of experimentally induced pain exhibit a decrease in motor unit discharge rate as well as a change in recruitment pattern.[12,13,14] In addition, a study by Descarreaux et al. showed that experimentally induced cutaneous pain to the lumbar region altered isometric trunk forces.[15]

Specific to the intramuscular EMG procedure, Smith et al. concluded its use appropriate for quantifying paraspinal muscle activation without significantly altering the trunk movement pattern. However, they examined the intramuscular EMG usage during walking and turning which requires only 
low-level muscle contractions (less than $20 \%$ of maximum activation).[16] It is currently unknown how intramuscular EMG affects muscle performance parameters during activities that involve high force muscle contractions. Therefore, the purpose of this study was to investigate the effects of insertion and presence of intramuscular EMG electrodes in lumbar multifidus muscles on muscle strength, endurance, activation, and fatigue during high-exertion lumbar spinal extension tasks. We hypothesized that the insertion and presence of fine-wire electrodes would lead to reduced muscle performance. This information is relevant to researchers who use intramuscular EMG to examine activities that involve high level of lower back muscle contraction. Clinically, applications that utilize intramuscular electrodes, e.g. diagnosis of lower back muscle dysfunction, biofeedback, and myoelectrically-controlled prosthetic development, may benefit from this work.

\section{Methods}

\subsection{Participants}

A sample of convenience of twenty individuals between 18-40 years of age participated ( 10 female, mean age $=25.7 \pm 3.5$, height $=1.73 \pm 0.09 \mathrm{~m}$, body mass $=74.3 \pm 14.3 \mathrm{~kg}$ ). The required sample size was estimated based on published data (estimated effect size $=0.41$, power $=0.95$ ). $[15]$ They were included in the study if they had no history of back pain in the last 6 months that required activity modification or medical care.[17] Exclusion criteria included spinal surgery, malignancy, stenosis, scoliosis, radiculopathic symptoms, contraindications of bleeding (e.g. clotting disorder), infection, fear of needles, and pregnancy. Informed consent as approved by the Institutional Review Board for Biomedical Research at XXX University was obtained from each participant.

\subsection{Procedures}

Participants were asked to attend 3 separate sessions of testing scheduled 5-10 days apart to allow full recovery.[18] They were instructed to refrain from exercise on the day of testing, and also to avoid 
strenuous exercise/activity 2 days before a testing session.[19] At the beginning of each session, the participants went through a standardized 10 minute warm-up that included walking, back rotations, extensions, and flexion callisthenic exercises. Session 1 involved surface EMG and muscle performance tests without intramuscular EMG (WO). Sessions 2 and 3 involved the same procedures as WO with one of the two intramuscular EMG conditions: with fine-wire electrodes present in the multifidus muscle during muscle performance tests (wire-in, WI) or immediate removal of the electrodes following insertion (insertion only, IO). The IO condition was achieved by removing the intramuscular electrodes with the guide needle. The order of these 2 conditions were randomized and the participants were blinded to the condition received.

\section{$\underline{\text { EMG Preparation }}$}

Participants were asked to lay prone on a treatment table with their lower back exposed. In all conditions, the skin over the lumbar spine and adjacent musculature was cleansed and lightly abraded with alcohol pads before a wireless surface EMG electrode (Trigno ${ }^{\mathrm{TM}}$, Delsys Inc., Natick, Massachusetts, USA) was placed over the lumbar paraspinal muscles at the L4 spinal level. L4 spinal level was determined by palpating the iliac crests and establishing the intercristal line.[20] Then the bony prominence of the L4 spinous process was located by further palpation and the aid of real-time sonography (General Electric NextGen LOGIQe, GE Healthcare Co., Milwaukee, Wisconsin, USA). In WI and IO conditions where intramuscular electrodes were applied, the same investigator used the sonographic unit and a guide needle (27 gauge, $30 \mathrm{~mm}$ in length, Natus Medical Inc., Pleasanton, California, USA) to insert the wire electrodes (paired hook, insulated alloy wires, Natus Medical Inc.) into the left lumbar multifidus muscle at the L4 spinal level (Figure 1). After implanting the intramuscular electrodes, the guide needle was removed, leaving the electrodes in place. Participants were told that they may or may not sense the presence of the fine-wire electrodes. Participants were then asked to perform a 
submaximal lumbar extensor contraction to set the wire electrodes in the muscle and to confirm EMG signal connection. In the IO condition, the wire electrodes were removed after this procedure. The participants were instructed to limit the amount of lumbar flexion after electrode placement in order to prevent dislodging the EMG electrodes in all conditions.

\section{$\underline{\text { Spinal Extension Muscle Performance Tests }}$}

Spinal extension strength was measured in torque $(\mathrm{Nm})$ using a dynamometer (Humac Norm $^{\mathrm{TM}}$; Computer Sports Medicine, Inc., Stoughton, Massachusetts, USA, Figure 2). Participants laid prone on the testing table of dynamometer with legs secured with straps. Axis of the dynamometer motor was aligned with the L4 spinal level.[21] During the test, participants contracted isometrically in a neutral spinal position against resistance applied to just inferior to the spine of scapula. The strength testing consisted of a submaximal practice trial followed by three, 5-second trials of maximum voluntary contraction (MVC). Each trial was separated by a 1-minute rest period. After this test, participants were provided a rest period of 5 minutes before the Sorensen test.

The Sorensen test for spinal extension endurance began with the participant lying prone on a table with anterior superior iliac spines (ASIS) aligned with the edge of the table (Figure 3).[22,23,24] A small bench was positioned so participants could use their arms for support and positioning until the test began. The participants' legs were supported by straps and an investigator. The same investigator provided stabilization for all participants during all sessions of testing. During the test, the participants placed their arms across the chest and held the body parallel to the ground, and were instructed to maintain this position for as long as possible. Termination of the test was determined by the participants' inability to maintain trunk position or when the participants voluntarily terminated the test. Pain data was collected from each participant using an 11-point visual analog scale (VAS)[25] prior to electrode placement, 
immediately after fine-wire EMG insertion, and prior to and immediate after the strength and endurance tests.

\subsection{Data Analysis}

Spinal extension strength was assessed as the highest torque recorded during the $3 \mathrm{MVC}$ trials. Endurance performance was measured as the Sorensen test time in seconds. EMG data were analyzed to determine the activation and fatigue patterns of the paraspinal muscles.[26] Data were filtered (10-450 Hz band-pass) and full-wave rectified. Reference activation level (100\%) was determined as the highest 1second EMG amplitude during the MVC trials. The muscle activation levels during the beginning (first $30 \mathrm{sec}$ ) and end (last $30 \mathrm{sec}$ ) of the Sorensen test were compared against the reference level. For muscle fatigue, power spectral analyses were performed using a fast Fourier transformation to determine the median frequency for each second of the Sorensen test. The median frequency values obtained were plotted over time and fitted with a regression line to determine the slope between these points. The time periods analyzed were the beginning and end of the trial (30 sec each), as well as the overall slope.[26] All EMG data analysis was conducted using a customized computer program (MATLAB ${ }^{\circ}$ version R2013a, The MathWorks, Inc., Natick, Massachusetts, USA).

\subsection{Statistical Analysis}

Statistical analyses were conducted using a software package (SPSS version 22.0, IBM Co., Armonk, New York, USA). One-way repeated measures ANOVAs were used to compare muscle torque, Sorensen test time, muscle activation levels, and median frequency slopes among the 3 conditions. Homogeneity of variance was tested with Mauchly's test. Where this was significant, Greenhouse-Geisser adjusted statistics were used. Post-hoc tests were conducted with Bonferroni correction to examine significant main effects. Significance level was set at .05 for all analyses. 
187

188

189

190

191

192

193

194

195

196

197

198

199

200

201

202

203

204

\section{Results}

Pain was rarely reported during any of the 3 conditions. The mean pain levels were $<1 / 10$ in all conditions. The highest report of pain was a 4/10 in only one participant during the Sorensen test in WI condition. There was no significant difference in muscle torque between the 3 conditions $(\mathrm{p}=.20)$. When comparing Sorensen test performance, there was a significant difference between the 3 conditions $(\mathrm{p}=.03$, Greenhouse-Geisser adjusted F=5.103; Table 1). Post-hoc comparison showed that the Sorensen test time in the IO condition was significantly longer than the WO condition $(161.3 \pm 58.5$ vs. $142.1 \pm 48.2 \mathrm{sec}$, $\mathrm{p}=.04)$.

There were no significant differences in muscle activation levels during the start and end of Sorensen test among the 3 conditions ( $\mathrm{p}=.68$ and .15 , respectively). Our results also showed no significant difference in overall median frequency slope $(\mathrm{p}=.12)$ and slopes during the beginning and end of the Sorensen test ( $\mathrm{p}=.98$ and .58 , respectively; Table 1$)$.

\section{Discussion}

Results of this study showed that the insertion and presence of intramuscular EMG fine-wire electrodes did not induce significant pain or affect muscle performance during high-exertion spinal extension tasks in individuals with no recent and current low back pain. Intramuscular EMG is widely used in studying activation of muscles that are inaccessible from the body surface such as the multifidus, however, until now there has been no conclusive evidence as to whether the invasive nature of intramuscular EMG procedure alters paraspinal muscle performance. Many of the previous studies investigating the relation between pain and paraspinal muscle function were conducted using experimentally-induced pain from hypertonic saline injection or electrical stimulation. Zedka et al. examined the paraspinal muscle function during simulated back pain induced by injections to the erector 
spinae muscles. They found that the painful stimuli decreased the velocity and range of trunk motion, and paraspinal muscle activation.[27] However, these findings may not translate to the use of intramuscular EMG because the pain ratings reported in their study were much higher (5-6/10). In fact, participants in our study reported low pain levels despite the insertion and presence of intramuscular electrodes during muscle performance tests. Our results agrees with the findings by Smith et al. who also reported minimal pain perception during walking $(<1 / 10)$ after intramuscular EMG electrode insertion.[16] The low pain levels experienced by our participants likely contributed to the similar muscle performance obtained during all 3 conditions of our experiment.

Even when the intensity of perceived pain is low, anticipation of pain still has the potential to alter movement performance.[28] Previous research has found that anticipated pain, more than actual pain, correlated with altered movement.[29] Related to the current study, Smith et al. assessed the anticipated and actual pain levels associated with fine-wire EMG insertion during walking tasks.[30] They found no significant difference in trunk mechanics during walking, and that low pain levels were reported throughout for both anticipated and actual pain levels.[30] Smith et al. hypothesized that because all participants were made aware of the testing procedure, including the intramuscular EMG procedures, those who were fearful and would have likely had higher anticipated pain opted to not participate.[30] Though we did not ask our participants to report their anticipated pain level, we did inform all potential participants about the invasive procedures necessary for placement of the intramuscular EMG devices. Therefore the individuals that did participate likely had low levels of anticipated pain which is reflective of the pain reports they provided during muscle performance testing.

One of the more interesting findings from this study was the significantly longer Sorensen test time in the IO condition when compared to WO. We attributed the consistent and slight increase in performance to a learning effect since we tested all participants in the WO condition first to avoid the possibility of persistent micro trauma from repeated intramuscular insertions. During the initial experience of the very strenuous Sorensen test, a sensorimotor memory may have developed that allowed 
the participants to achieve consistent levels of performance despite experiencing low levels of pain during the subsequent conditions (WI and IO).[31] Even though we did not inform the participants about their Sorensen test performance, this sensorimotor memory may have provided a reference level of exertion and motivated to participants to achieve greater performance and contributing to the learning effect.[32] Furthermore, a previous study by Brotons-Gil et al. has shown that simple tasks performed using the trunk muscles are susceptible to learning effect.[33] In their study, participants performance during a flexion-rotation trunk test improved during repeated tests despite long intervals of time ( 7 days) between tests. While the Sorensen test has been demonstrated to be reliable,[24] learning effects and other psychological factors affecting this test should be considered in future studies.[34]

\section{Limitations}

While our data indicated that intramuscular fine-wire electrodes do not significantly impact muscle performance during high-exertion spinal extension activities, we would like to caution the readers when extrapolating our results. First, both muscle performance tasks (extension strength and endurance tests) are isometric in nature; pain level and muscle performance might change during tasks that involve dynamic excursion of the spine and muscles over a larger range. Second, our study was limited to a single unilateral intramuscular EMG electrode insertion. It is possible that multiple insertions may induce substantially higher levels of discomfort and alter the results. Finally, participants in the current study were free of recent activity-limiting LBP. Perception and sensitivity to pain in the lower back region are likely to be different in individuals with chronic pain.[35,36]

\section{Conclusion}


Our findings suggested the sonographically-guided insertion and presence of fine-wire intramuscular EMG electrodes in the lumbar multifidus muscles had no significant impact on spinal extension muscle strength and endurance. This study provides important technical evidence to support that implementing intramuscular EMG does not affect muscle performance during high-exertion contractions (50-100\% of MVIC) in individuals without a recent history of lower back pain.

\section{ACKNOWLEDGMENT}

This research study was made possible by the 2015 University of Nevada, Las Vegas Physical Therapy Student Opportunity Research Grant. We would like to thank James Dimascio and Rebeka Hicks for their contribution to data collection and analysis. 
1. Hoy D, Bain C, Williams G, et al. A systematic review of the global prevalence of low back pain. Arthritis Rheum 2012; 64(6):2028-2037.

2. Panjabi MM. The stabilizing system of the spine. Part I. Function, dysfunction, adaptation, and enhancement. J Spinal Disord 1992; 5(4):383-389; discussion 397.

3. Crisco JJ, Panjabi MM, Yamamoto I, Oxland TR. Euler stability of the human ligamentous lumbar spine. Part II: Experiment. Clin Biomech (Bristol, Avon) 1992; 7(1):27-32.

4. Moseley GL, Hodges PW, Gandevia SC. Deep and superficial fibers of the lumbar multifidus muscle are differentially active during voluntary arm movements. Spine (Phila Pa 1976) 2002; 27(2):E29-36. 5. Wallwork TL, Stanton WR, Freke M, Hides JA. The effect of chronic low back pain on size and contraction of the lumbar multifidus muscle. Man Ther 2009; 14(5):496-500.

6. Ward SR, Kim CW, Eng CM, et al. Architectural analysis and intraoperative measurements demonstrate the unique design of the multifidus muscle for lumbar spine stability. J Bone Joint Surg Am 2009; 91(1):176-185.

7. Barr KP, Griggs M, Cadby T. Lumbar stabilization: core concepts and current literature, Part 1. Am J Phys Med Rehabil 2005; 84(6):473-480.

8. Kjaer P, Bendix T, Sorensen JS, Korsholm L, Leboeuf-Yde C. Are MRI-defined fat infiltrations in the multifidus muscles associated with low back pain? BMC Med 2007; 5:2.

9. Farina D, Gazzoni M, Merletti R. Assessment of low back muscle fatigue by surface EMG signal analysis: methodological aspects. J Electromyogr Kinesiol 2003; 13(4):319-332.

10. McGill S, Juker D, Kropf P. Appropriately placed surface EMG electrodes reflect deep muscle activity (psoas, quadratus lumborum, abdominal wall) in the lumbar spine. J Biomech 1996; 29(11):1503-1507. 11. Stokes IA, Henry SM, Single RM. Surface EMG electrodes do not accurately record from lumbar multifidus muscles. Clinical biomechanics 2003; 18(1):9-13.

12. Graven-Nielsen T, Lund H, Arendt-Nielsen L, Danneskiold-Samsoe B, Bliddal H. Inhibition of maximal voluntary contraction force by experimental muscle pain: a centrally mediated mechanism. Muscle Nerve 2002; 26(5):708-712.

13. Farina D, Arendt-Nielsen L, Merletti R, Graven-Nielsen T. Effect of experimental muscle pain on motor unit firing rate and conduction velocity. J Neurophysiol 2004; 91(3):1250-1259.

14. Farina D, Arendt-Nielsen L, Graven-Nielsen T. Experimental muscle pain reduces initial motor unit discharge rates during sustained submaximal contractions. J Appl Physiol (1985) 2005; 98(3):999-1005. 15. Descarreaux M, Blouin JS, Teasdale N. Isometric force production parameters during normal and experimental low back pain conditions. BMC Musculoskelet Disord 2005; 6:6.

16. Armour Smith J, Kulig K. Does insertion of intramuscular electromyographic electrodes alter motor behavior during locomotion? J Electromyogr Kinesiol 2015; 25(3):431-437.

17. Falla D, Gizzi L, Tschapek M, Erlenwein J, Petzke F. Reduced task-induced variations in the distribution of activity across back muscle regions in individuals with low back pain. Pain 2014; 155(5):944-953.

18. Koumantakis GA, Arnall F, Cooper RG, Oldham JA. Paraspinal muscle EMG fatigue testing with two methods in healthy volunteers. Reliability in the context of clinical applications. Clin Biomech (Bristol, Avon) 2001; 16(3):263-266.

19. Trost Z, France CR, Thomas JS. Pain-related fear and avoidance of physical exertion following delayed-onset muscle soreness. Pain 2011; 152(7):1540-1547.

20. Chakraverty R, Pynsent P, Isaacs K. Which spinal levels are identified by palpation of the iliac crests and the posterior superior iliac spines? J Anat 2007; 210(2):232-236. 
21. Yoshioka T, Tsuji H, Hirano N, Sainoh S. Motion characteristic of the normal lumbar spine in young adults: instantaneous axis of rotation and vertebral center motion analyses. J Spinal Disord 1990; 3(2):103-113.

22. Coorevits P, Danneels L, Cambier D, Ramon H, Vanderstraeten G. Assessment of the validity of the Biering-Sorensen test for measuring back muscle fatigue based on EMG median frequency characteristics of back and hip muscles. J Electromyogr Kinesiol 2008; 18(6):997-1005.

23. Demoulin C, Vanderthommen M, Duysens C, Crielaard JM. Spinal muscle evaluation using the Sorensen test: a critical appraisal of the literature. Joint, bone, spine : revue du rhumatisme 2006; 73(1):43-50.

24. Latimer J, Maher CG, Refshauge K, Colaco I. The reliability and validity of the Biering-Sorensen test in asymptomatic subjects and subjects reporting current or previous nonspecific low back pain. Spine (Phila Pa 1976) 1999; 24(20):2085-2089; discussion 2090.

25. Bijur PE, Silver W, Gallagher EJ. Reliability of the visual analog scale for measurement of acute pain. Acad Emerg Med 2001; 8(12):1153-1157.

26. Beneck GJ, Baker LL, Kulig K. Spectral analysis of EMG using intramuscular electrodes reveals nonlinear fatigability characteristics in persons with chronic low back pain. J Electromyogr Kinesiol 2013; 23(1):70-77.

27. Zedka M, Prochazka A, Knight B, Gillard D, Gauthier M. Voluntary and reflex control of human back muscles during induced pain. J Physiol 1999; 520 Pt 2:591-604.

28. Pincus T, Vogel S, Burton AK, Santos R, Field AP. Fear avoidance and prognosis in back pain: a systematic review and synthesis of current evidence. Arthritis Rheum 2006; 54(12):3999-4010.

29. Vlaeyen JW, Linton SJ. Fear-avoidance and its consequences in chronic musculoskeletal pain: a state of the art. Pain 2000; 85(3):317-332.

30. Armour Smith J, Kulig K. Does insertion of intramuscular electromyographic electrodes alter motor behavior during locomotion? J Electromyogr Kinesiol 2015.

31. Cole KJ, Potash M, Peterson C. Failure to disrupt the 'sensorimotor' memory for lifting objects with a precision grip. Exp Brain Res 2008; 184(2):157-163.

32. Hopkins WG. Measures of reliability in sports medicine and science. Sports Med 2000; 30(1):1-15. 33. Brotons-Gil E, Garcia-Vaquero MP, Peco-Gonzalez N, Vera-Garcia FJ. Flexion-rotation trunk test to assess abdominal muscle endurance: reliability, learning effect, and sex differences. J Strength Cond Res 2013; 27(6):1602-1608.

34. Mannion AF, O'Riordan D, Dvorak J, Masharawi Y. The relationship between psychological factors and performance on the Biering-Sorensen back muscle endurance test. Spine J 2011; 11(9):849-857. 35. de Lussanet $\mathrm{MH}$, Behrendt F, Puta C, et al. Impaired visual perception of hurtful actions in patients with chronic low back pain. Hum Mov Sci 2013; 32(5):938-953.

36. Naliboff BD, Cohen MJ, Swanson GA, Bonebakker AD, McArthur DL. Comprehensive assessment of chronic low back pain patients and controls: physical abilities, level of activity, psychological adjustment and pain perception. Pain 1985; 23(2):121-134. 


\begin{tabular}{|l|l|l|l|l|}
\hline & Wire Out (WO) & Wire In (WI) & Insertion Only (IO) & p value \\
\hline Peak Extension Torque (Nm) & $116.2 \pm 37.3$ & $120.7 \pm 38.3$ & $118.4 \pm 34.9$ & 0.196 \\
\hline Sorensen Test Performance (sec) & $142.1 \pm 48.2$ & $156.0 \pm 58.5$ & $161.3 \pm 58.5$ & 0.025 \\
\hline $\begin{array}{l}\text { Median Frequency Slope } \\
\text { (overall; Hz/s) }\end{array}$ & $-0.40 \pm 0.16$ & $-0.44 \pm 0.20$ & $-0.42 \pm 0.18$ & 0.120 \\
\hline $\begin{array}{l}\text { Median Frequency Slope } \\
\text { (first 30 sec; Hz/sec) }\end{array}$ & $-0.26 \pm 0.67$ & $-0.66 \pm 0.46$ & $-0.47 \pm 0.54$ & 0.982 \\
\hline $\begin{array}{l}\text { Median Frequency Slope } \\
\text { (last 30 sec; Hz/sec) }\end{array}$ & $-0.51 \pm 0.41$ & $-0.38 \pm 0.51$ & $-0.55 \pm 0.45$ & 0.578 \\
\hline $\begin{array}{l}\text { Percent of Activation during Sorensen } \\
\text { Test (first 30 sec; } \% \text { ) }\end{array}$ & $50.3 \pm 13.0$ & $53.2 \pm 17.6$ & $49.5 \pm 13.7$ & 0.676 \\
\hline $\begin{array}{l}\text { Percent of Activation during Sorensen } \\
\text { Test (last 30 sec; \%) }\end{array}$ & $60.3 \pm 13.9$ & $57.0 \pm 16.5$ & $55.6 \pm 19.4$ & 0.154 \\
\hline
\end{tabular}

365 Table 1: Comparison of Muscle Performance in Three Test Conditions (WO: without insertion and 366 presence of wire electrodes; WI: with insertion and presence of wire electrodes; IO: insertion of wire

367 electrodes followed by removal, electrodes not present in the muscle during performance testing) 

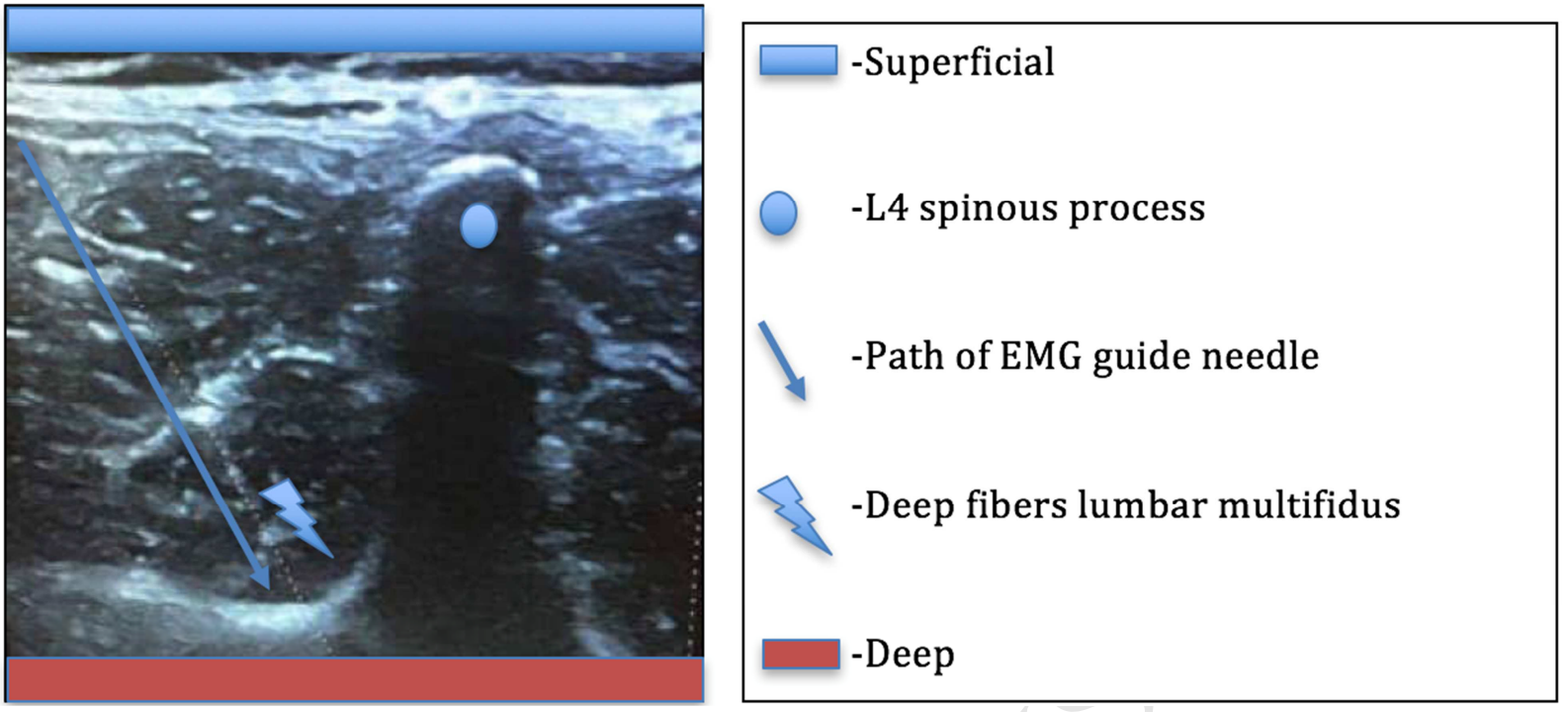

Figure 1: Axial Sonographic Image Demonstrating the Guided Insertion of the Wire EMG Electrodes 


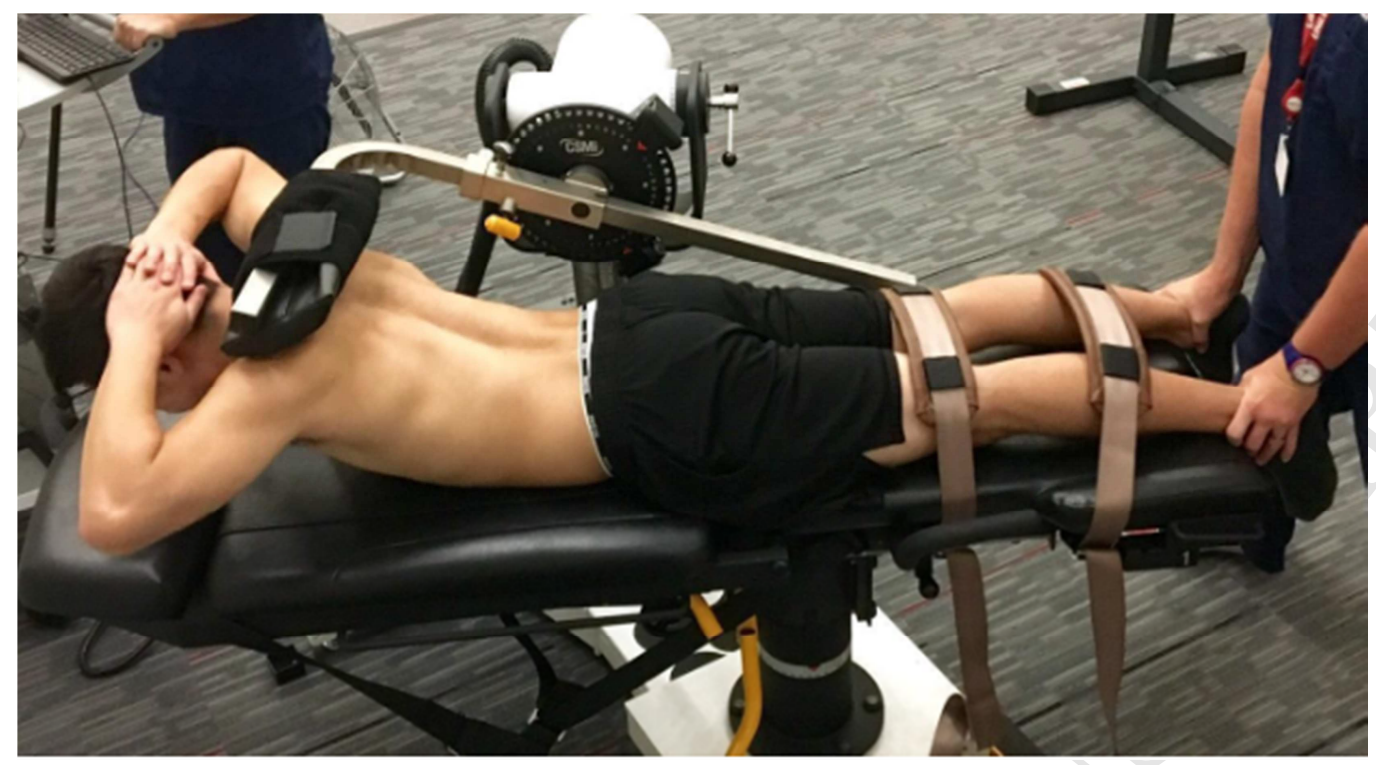

Figure 2: Maximal Voluntary Isometric Contraction Test for Spinal Extension Strength 


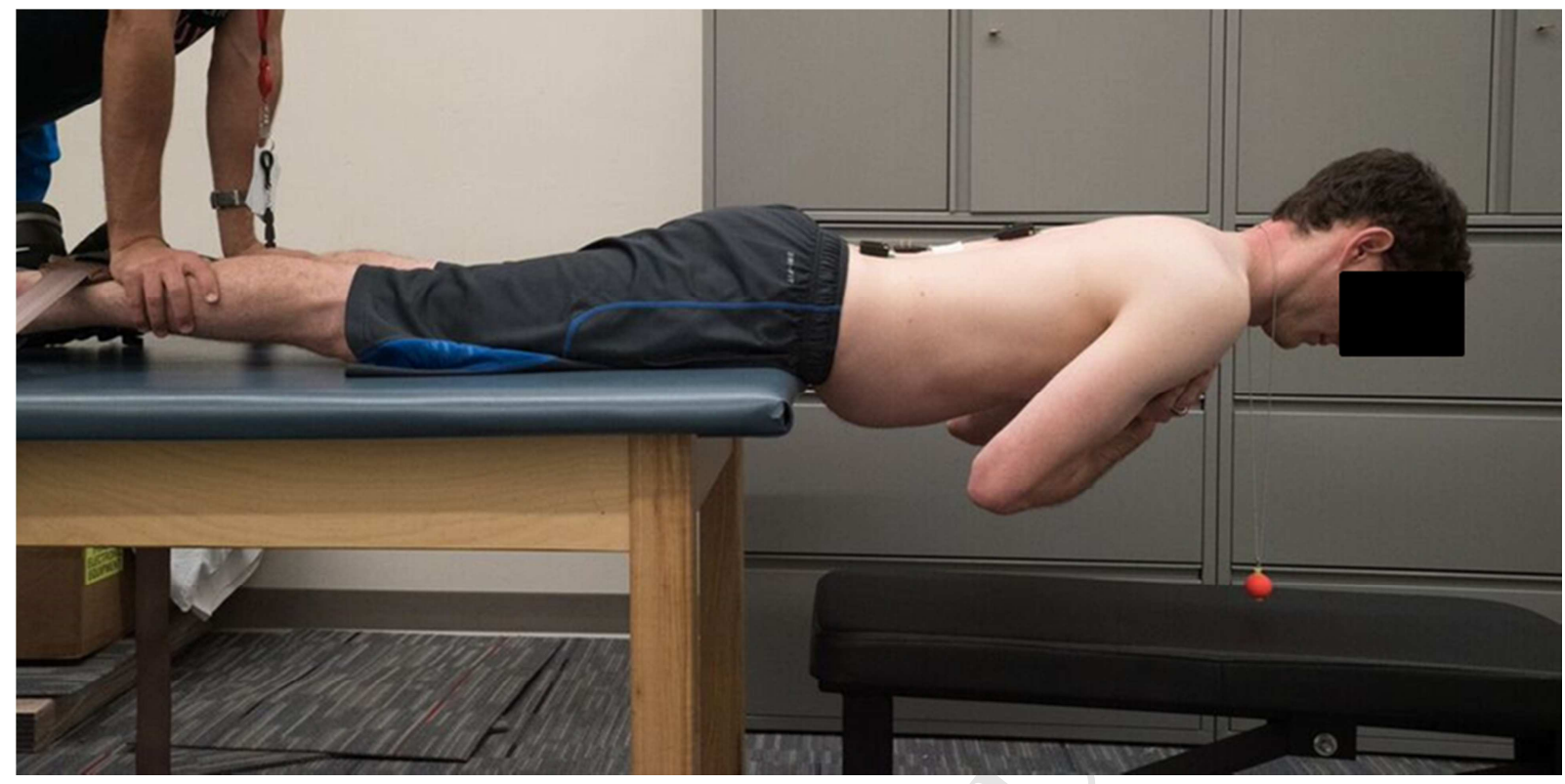

Figure 3: The Sorensen Test for Paraspinal Muscle Endurance 